\title{
Age-related alteration of poly(ADP-ribose) polymerase activity in different parts of the brain
}

\author{
Joanna B. Strosznajder ${ }^{1 凶}$, Henryk Jęśko ${ }^{1}$ and Robert P. Strosznajder ${ }^{2}$ \\ Polish Academy of Sciences, Medical Research Centre, ${ }^{1}$ Department of Cellular Signalling, and \\ ${ }^{2}$ Department of Neurophysiology, A. Pawińskiego 5, 02-106 Warszawa, Poland
}

Received: 9 March, 2000

Key words: PARP, brain, aging

\begin{abstract}
Poly(ADP-ribose) polymerase (PARP) is a conserved enzyme involved in the regulation of DNA repair and genome stability. The role of PARP during aging is not well known. In this study PARP activity was investigated in nuclear fractions from hippocampus, cerebellum, and cerebral cortex of adult (4 months), old adult (14 months) and aged (24-27 months) rats. Concomitantly, the free radical evoked lipid peroxidation was estimated as thiobarbituric acid reactive substances (TBARS).

The specific activity of PARP in adult brain was about 25,21 and $16 \mathrm{pmol} / \mathrm{mg}$ protein per min in hippocampus, cerebellum and cerebral cortex, respectively. The enzyme activity was higher in all investigated parts of the brain of old adults. In aged animals PARP activity was lower in hippocampus by about $50 \%$, and was unchanged in cerebral cortex and in cerebellum comparing to adult rats. The concentration of TBARS was the same in all parts of the brain and remained unchanged during aging. There is no direct correlation between PARP activity and free radical evoked lipid peroxidation during brain aging. The lowered enzyme activity in aged hippocampus may decrease DNA repair capacity which subsequently may be responsible for the higher vulnerability of hippocampal neurons to different toxic insults.
\end{abstract}

Poly(ADP-ribose) polymerase (PARP, EC 2.4.2.30) an evolutionally conserved enzyme, has been found in almost all nucleated cells of higher eukaryotes. DNA interruptions, mainly single strand breaks, activate PARP. The enzyme catalyses the reaction of
poly(ADP-ribosyl)ation of numerous nuclear proteins including histones and PARP itself as a main acceptor. This process causes temporal chromatin disassembly and attracts DNA repair enzymes (Realini \& Althaus, 1992; Masson et al., 1998). It has been sug-

\footnotetext{
This work was supported by the State Committee for Scientific Research (KBN, Poland) grant No. 4.P05A.051.12

${ }^{\bowtie}$ Author for correspondence: Joanna Strosznajder, tel: (48 22) 608 6414, fax: (48 22) 668 5223; e-mail: joannas@cmdik.pan.pl
}

Abbreviations: PARP, poly(ADP-ribose) polymerase; TBARS, thiobarbituric acid reactive substances. 
gested that oxidative damage of cellular components, including DNA, occurs during brain aging. However, data concerning the role of PARP during brain aging are controversial and inconsistent. Messripour et al. (1994) found that PARP activity and enzyme protein level in neurons and astrocytes of whole rat brain increased by over three times in 30 month-old rats compared to 3 month-old controls. Salminen et al. (1997) observed a significant decline of PARP protein level in replicatively senescent cultured fibroblasts. Age-related decline of PARP activity in brain and other tissues, and in cell lines was also observed by Mishra \& Das (1992), Quesada et al. (1990), and Grube \& Bürkle (1992). Maximal PARP activity (stimulated with oligonucleotides) in mammalian mononuclear leukocytes was also determined by Grube \& Bürkle (1992). They found a positive correlation between specific PARP activity and mean and maximal life span of the 13 mammalian donor species. The amount of PARP protein was not changed. The highest specific activity of PARP with no changes in enzyme protein level was found in human cell lines derived from centenarians (Muiras et al., 1998).

It is suggested that this enhancement of PARP activity may be important for long-term maintenance of genome integrity and may contribute to longevity (Muiras et al., 1998).

The aim of this study was to investigate PARP activity in different parts of the brain during aging. In addition, free radical-evoked lipid peroxidation was evaluated in aging brain and correlated with PARP activity. A preliminary report of this work was published (Strosznajder et al., 1999).

\section{MATERIALS AND METHODS}

Male Wistar rats 4, 14 and 24-27 months old (adult, old adult and aged, respectively) were from the Animal Breeding House of Medical Research Centre, Polish Academy of Science (Warszawa, Poland). [Ade- nine- $\left.{ }^{14} \mathrm{C}\right] \mathrm{NAD}$ sp. ac. $9.32 \mathrm{~GB} / \mathrm{mmol}$ and ECL reagents were from Amersham (Buckinghamshire, U.K.). Other reagents were from Sigma (St. Louis, U.S.A.). Polyclonal anti-PARP antibody was a gift from Prof. Kunihiro Ueda (Kyoto University, Japan).

Rats were decapitated and brains were rapidly removed. The hippocampus, cerebellum and brain cortex were isolated and dissected. A $10 \%$ homogenate was obtained by homogenization of dissected brain parts in a Douncetype glass homogenizer in $0.32 \mathrm{M}$ sucrose with $10 \mathrm{mM}$ Tris/HCl, $\mathrm{pH}$ 7.4. The homogenate $(10 \%, \mathrm{w} / \mathrm{v})$ was centrifuged for $3 \mathrm{~min}$ at $1100 \mathrm{~g}$. The pellet $\left(\mathrm{P}_{1}\right)$ containing the nuclear fraction was used for the experiments.

Determination of PARP activity. The PARP activity was determined according to Ueda et al. $(1982 ; 1991)$ using $\left[\right.$ adenine $-{ }^{14} \mathrm{C}$ ] NAD as a substrate. The incubation mixture contained $200 \mu \mathrm{M}\left[{ }^{14} \mathrm{C}\right] \mathrm{NAD} 2 \times 10^{5}$ d.p.m., $100 \mathrm{mM}$ Tris/HCl buffer, $\mathrm{pH} 8.0,10 \mathrm{mM}$ $\mathrm{MgCl}_{2}, 1 \mathrm{mM}$ dithiothreitol (DTT), $50 \mu \mathrm{M}$ p-amidinophenylmethanesulfonyl fluoride (APMSF), $200 \mu \mathrm{g}$ of protein. The final volume was $100 \mu \mathrm{l}$ and it was incubated for $5 \mathrm{~min}$ at $37^{\circ} \mathrm{C}$. Then the reaction was stopped with 0.8 $\mathrm{ml}$ of ice-cold $25 \%$ trichloroacetic acid (TCA). Precipitates were collected on Whatman GF/B filters, washed five times with $3 \mathrm{ml}$ of $5 \%$ TCA and dried. The radioactivity was determined using an LKB Wallac 1409 scintillation counter.

Determination of thiobarbituric acid reactive substances. Thiobarbituric acid reactive substances (TBARS), including malondialdehyde, the last products of lipid peroxidation, were determined according to Asakawa \& Matsushite (1980). The brain cortex, hippocampus and cerebellum were homogenized in ice-cold $10 \mathrm{mM}$ Tris/HCl buffer, $\mathrm{pH}$ 7.4. The homogenates were resuspended in $10 \mathrm{mM}$ Tris/HCl buffer, $\mathrm{pH} 7.4$ at protein concentrations of approx. $0.5 \mathrm{mg} / \mathrm{ml}$ and incubated for $5 \mathrm{~min}$. After incubation $1 \mathrm{ml}$ of $30 \%$ TCA, $0.1 \mathrm{ml}$ of $5 \mathrm{~N} \mathrm{HCl}$ and $0.75 \%$ 
thiobarbituric acid were added. The tubes were capped and the mixture was heated at $100^{\circ} \mathrm{C}$ for $15 \mathrm{~min}$ in boiling water bath. After centrifugation, the absorbance of the supernatant was determinated at $535 \mathrm{~nm}$ against the reagent blank.

Western blot analysis. Homogenate or nuclear fractions from brain cortex and hippocampus were used for Western blot. Samples were examined using tricine sodium dodecyl sulphate/polyacrylamide gel electrophoresis described by Schägger \& Von Jagow (1987). Briefly, the protein samples were heated in buffer containing $37.5 \mu \mathrm{l} / \mathrm{ml} \beta$-mercaptoethanol at $95^{\circ} \mathrm{C}$ for $5 \mathrm{~min}$ and then loaded in aliquots of $50 \mu \mathrm{g}$ of protein per lane onto a discontinuous gel system consisting of stacking (4\%) and separating (7.5\%) gels. Electrophoresis was performed at $200 \mathrm{~V}$ for $45 \mathrm{~min}$. The separating gel was $55 \mathrm{~mm}$ long. After electrophoresis the proteins were transferred for $3 \mathrm{~h}$ at $4^{\circ} \mathrm{C}$ into a nitrocellulose membrane. Then the membrane was left overnight in a phosphate buffer solution containing $5 \%$ milk (fatt free) and Triton X-100 (PBS-T). The membranes were incubated at room temperature with a primary polyclonal antibody against PARP diluted 1:300 (polyclonal rabbit antibody against PARP) in $0.25 \%$ milk for $2 \mathrm{~h}$. The membranes were washed 3 times for $15 \mathrm{~min}$ in PBS/Tween-20, and then were incubated with horseradish peroxide-linked secondary antibody diluted $1: 1000$ in $0.25 \%$ milk for 60 min. Then were washed 3 times in PBS $0.005 \%$ Tween-20 and once for 15 min with PBS. The membrane was dried and protein was visualised with an ECL kit as recommended in manufacturer's protocol.

The Ethics Committee accepted the research project.

\section{RESULTS}

It was observed that specific activity of PARP in nuclear fraction from adult rat brain was higher in hippocampus than in cerebel- lum and was the lowest in cerebral cortex and reached the value of $24.78 \pm 2.98,20.82 \pm$ 4.09 , and $15.52 \pm 3.94 \mathrm{pmol} / \mathrm{mg}$ protein per min respectively (Fig. 1-3A). In hippocampus from 14 months old animals PARP activity was about two fold higher than in control (4 months old). However, in aged rats (24-27 months old) the enzyme activity was significantly lower then, observed in control group. (Fig. 1A). The Western blot analysis indicated no alteration in PARP protein content (data
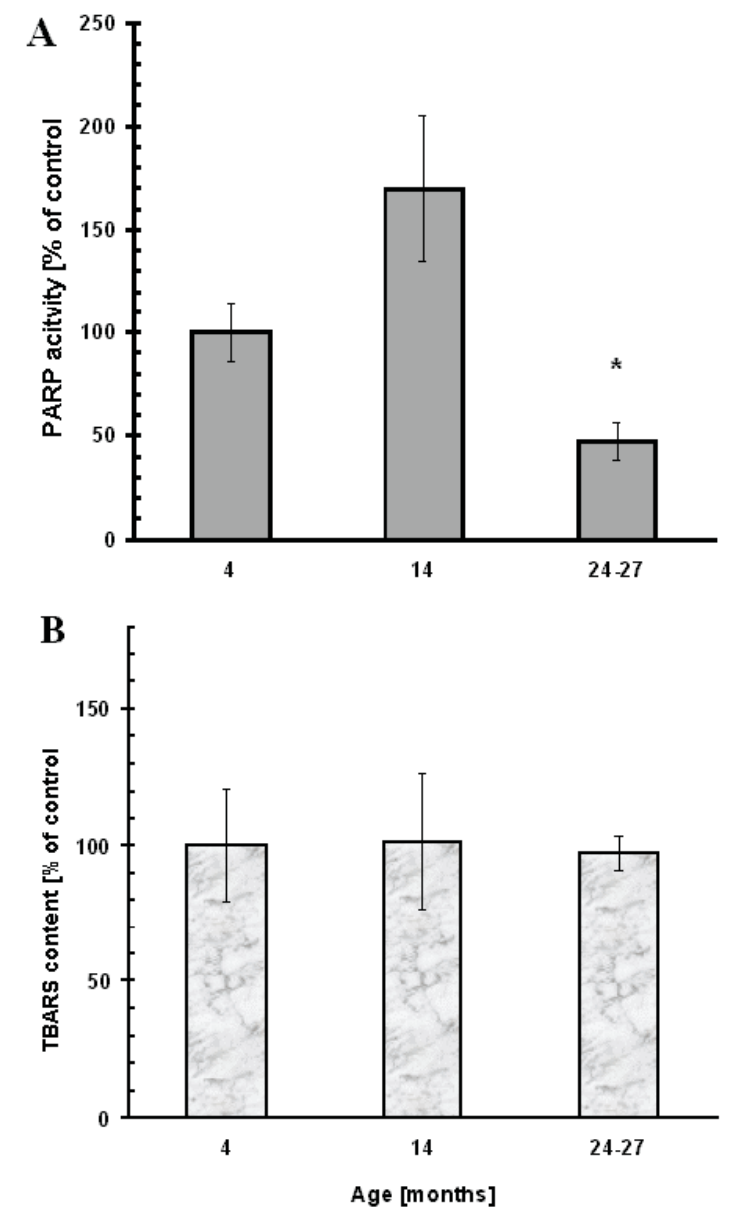

Figure 1. Age-related changes of PARP activity (A) and TBARS concentration (B) in rat hippocampus.

Data are means \pm S.E.M. from three experiments, each carried out in triplicate, presented as percentage of control value. The control value for PARP activity was $24.78 \pm 2.98 \mathrm{pmol} / \mathrm{mg}$ protein per min from 3 experiments, each carried out in triplicate. The control value for TBARS was $1.91 \pm 0.39 \mathrm{nmol} / \mathrm{mg}$ protein from 5 experiments, each carried out in triplicate. Statistical significance was evaluated by Student's $t$-test, ${ }^{*} P<0.02$ (as compared to control). 
not shown). In cerebral cortex PARP activity was insignificantly higher in 14 and 24-27 months old animals compared to control (Fig. 2A). In cerebellum of 14 months old animals PARP activity was significantly increased about two fold while in aged rats this enzyme activity was close to the control value (Fig. 3A). Concomitantly free radical-evoked lipid peroxidation was measured as the level of the last products of lipid peroxidations aldehydes and ketones reacting with thiobarbituric acid reactive substances (TBARS). It was found that concentration of TBARS was similar in all investigated parts of the adult brain and it was not significantly changed during aging (Fig. 1-3B). However, during incubation of brain homogenates for $60 \mathrm{~min}$ at $37^{\circ}$ a significantly higher accumulation of TBARS was observed in hippocampus comparing to the other parts of the brain (Table 1). This enhancement of TBARS level during incubation of homogenates from hippocampus, brain cortex and cerebellum was similar in 4, 14, and 24-27 months old animals (Table 1).

\section{DISCUSSION}

Our results indicate an aged related alteration of PARP activity in different parts of the brain. We observed an enhancement of PARP activity in all three parts of the brain of old adult animals. This increase of PARP specific activity may be considered as an early indicator of DNA damage. It is possible that higher radical oxygen species (ROS) formation and DNA damage observed by Mecocci et al. (1993), Ashok et al. (1998), Lu et al. (1999), Edris et al. (1994) during aging may be responsible for this activation of PARP in old adult animals. However, significantly lower PARP activity in aged hippocampus may be explained by lower gene expression, covalent modification of the enzyme, or interaction with other nuclear factors. Mishra \& Das (1991) showed a sharp decline in PARP activity in testis of aged rats. Das \& Kanungo
(1986) reported a decline in PARP activity in brain of rats during development. Mishra \& Das (1992) presented data on a sharp
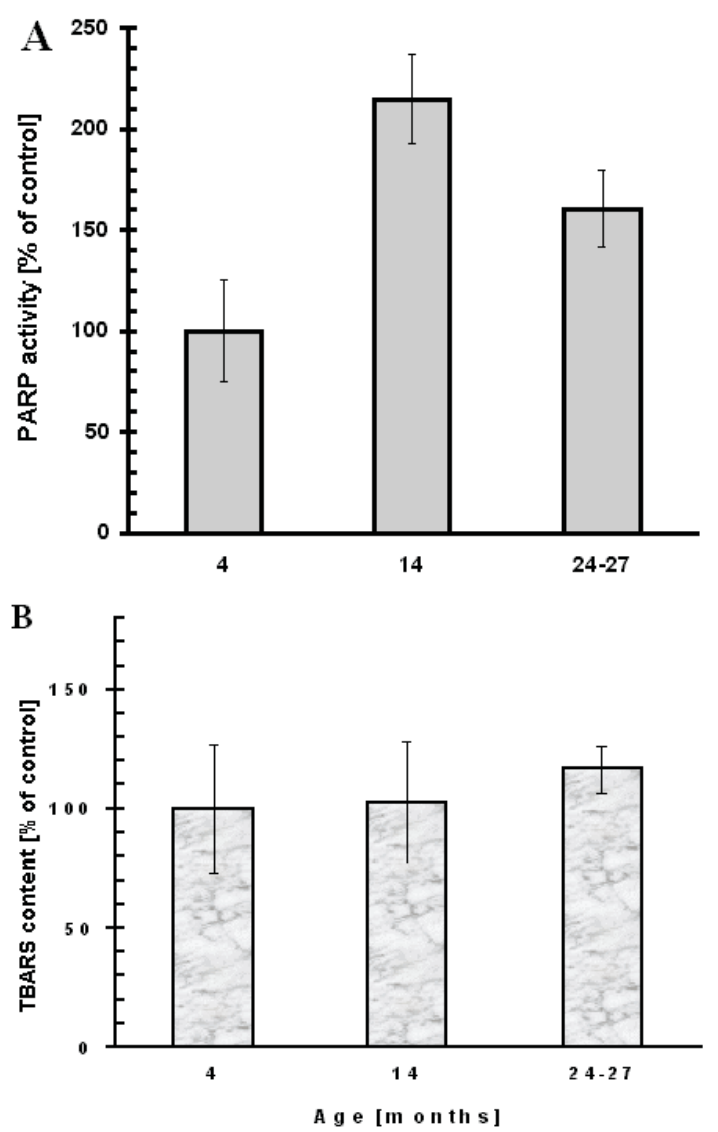

Figure 2. Age-related changes of PARP activity (A) and TBARS concentration $(B)$ in rat cerebral cortex.

Data are means \pm S.E.M. from two experiments, each carried out in triplicate, presented as percentage of control value. The control value for PARP activity was $15.52 \pm 3.94 \mathrm{pmol} / \mathrm{mg}$ protein per min from 3 experiments, each carried out in triplicate. The control value for TBARS was $1.84 \pm 0.25 \mathrm{nmol} / \mathrm{mg}$ protein from 5 experiments, each carried out in triplicate.

age-related decline of (ADP-ribosyl)ation of chromosomal proteins in brain and liver of rats. Their findings together with the data of Chaturvedi \& Kanungo (1983) suggest that progressive condensation of chromatin along with aging may be responsible for the decline in PARP activity in old age. Our data suggest that the decrease of PARP activity in hippocampus may be responsible for the lower abil- 
ity of DNA to undergo repair in this part of the brain and for the higher vulnerability of
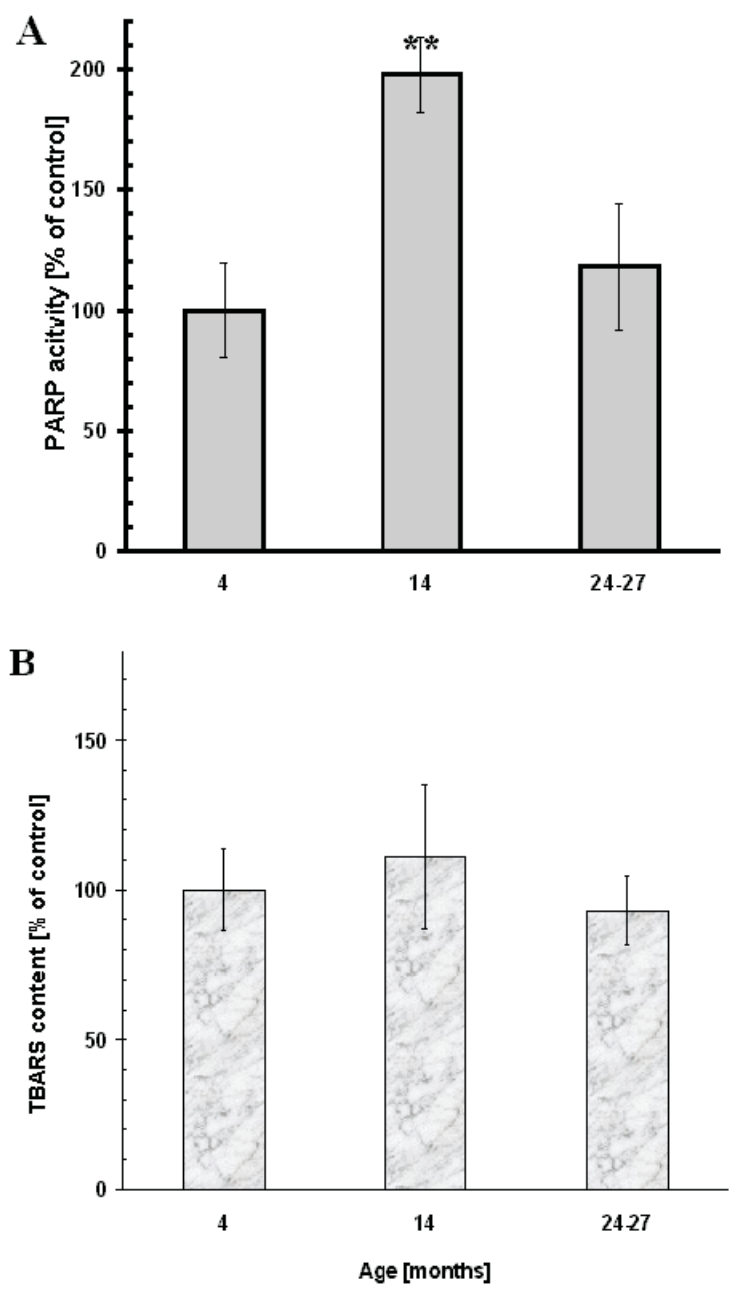

Figure 3. Age-related changes of PARP activity (A) and TBARS concentration $(B)$ in rat cerebellum.

Data are means \pm S.E.M. from three experiments, each carried out in triplicate, presented as percentage of control value. The control value for PARP activity was $20.82 \pm 4.09 \mathrm{pmol} / \mathrm{mg}$ protein per min from 3 experiments, each carried out in triplicate. The control value for TBARS was $1.63 \pm 0.44 \mathrm{nmol} / \mathrm{mg}$ protein from 5 experiments, each carried out in triplicate. Statistical significance was evaluated by Student's $t$-test, ${ }^{* *} P<0.01$ (as compared to control).

hippocampal neurones to toxic insults. During incubation a higher accumulation of TBARS was observed in hippocampus compared to cerebral cortex and cerebellum. However, TBARS concentration was the same in all parts of the brain and was not changed during aging. In many studies oxidative damage is suggested to be an important factor in ag- ing. However, there is no consensus about the free radicals theory because negative or inconclusive evidences has also been obtained (Starke-Read, 1997).

The decreased PARP activity may have influence on the reduced functional activity of hippocampal neurones in old age due to the possible involvement of poly(ADP-rybosyl)ation of chromosomal proteins in several aspects of gene expression as it was suggested previously by Mishra \& Das (1992). It has been suggested that the decrease in poly(ADP-ribosyl)ation of nuclear proteins and also non histone proteins in old age may refer to the lower transcriptional activity of chromatin (Tanigawa et al., 1976). However, Messripour et al. (1994) reported up-regulation of PARP protein level and its higher activity in cells isolated from the whole aged brain. Up till now there have been many controversions in the literature on age-related alterations of PARP activity. The reason for such discrepancies could be different experimental models and materials used by different groups. Changes in intracellular distribution of protein are possible since several groups reported the existence of an extranuclear population of PARP (Chypre et al., 1988; Cookson et al., 1999). Qualitative changes in the enzyme itself may also occur during aging. Moreover, it is impossible to exclude an influence of signal transduction processes that can be changed during aging. Cohen-Armon et al. (1999) reported that activation of poly(ADP-rybosyl)ation is mediated by phospholipase $\mathrm{C}$ and inositol 1,4,5-trisphosphate $\left(\mathrm{IP}_{3}\right)$ dependent $\mathrm{Ca}^{2+}$ release. These results suggested that PARP could be a new target for cholinergic receptor dependent signal transduction pathway. The latest studies of Ayyagari et al. (1998) indicate that this pathway is significantly affected by aging. Moreover, several groups have shown that PARP could serve as a substrate for protein kinases that may change PARP activity (Ruscetti et al., 1998). 
Table 1. Accumulation of TBARS in different parts of the brain.

Homogenates from hippocampus, cerebral cortex and cerebellum from 4, 14, 24-27 months old animals were incubated in Krebs-Henseleit buffer at $\mathrm{pH} 7.4$ for $60 \mathrm{~min}$ at $37^{\circ} \mathrm{C}$. TBARS were determined as described in Material and Methods. The value are means \pm S.E.M. from 3-5 experiments carried out in triplicate.

\begin{tabular}{lccc}
\hline Age (months) & \multicolumn{3}{c}{ TBARS nmol/mg protein } \\
\hline & Hippocampus & Cerebral cortex & Cerebellum \\
4 & $1.04 \pm 0.59(5)$ & $0.28 \pm 0.09(5)$ & $0.63 \pm 0.37(5)$ \\
14 & $0.85 \pm 0.51(4)$ & $0.43 \pm 0.35(4)$ & $0.71 \pm 0.34(4)$ \\
$24-27$ & $1.00 \pm 0.55(3)$ & $0.33 \pm 0.08(3)$ & $0.41 \pm 0.05(5)$ \\
\hline
\end{tabular}

Our results show a significant decrease of PARP activity in hippocampus of aged animals. The lower PARP activity may be responsible for the lower ability of DNA to undergo repair and higher vulnerability of hippocampal neurons to different toxic insults.

\section{R E F E R E N C ES}

Asakawa, T. \& Matsushita, S. (1980) Coloring conditions of thiobarbituric acid test for detecting lipid hydroperoxides. Lipids 15, 137-140.

Ashok, B.T., Ahmad, J. \& Ali, R. (1998) Immunochemical detection of oxidative DNA damage in cancer and aging using anti-reactive oxygen species modified DNA monoclonal antibody. Int. J. Biochem. Cell. Biol. 30, 1367-1377.

Ayyagari, P.U., Gerber, M., Joseph, J.A. \& Crews, F.T. (1998) Uncoupling of muscarinic cholinergic phosphoinositide signals in senescent cerebral cortical and hippocampal membranes. Neurochem. Int. 32, 107-115.

Chaturvedi, M.M. \& Kanungo, M.S. (1983) Analysis of chromatin of the brain of young and old rats by micrococcal nuclease and DNase I. Biochem. Int. 6, 357-363.

Chypre, C., Maniez, C. \& Mandel, P. (1988) Cytoplasmic poly(ADP-ribose) polymerase associated with free messenger ribonucleoprotein particles in rat brain. J. Neurochem. 51, 561-565.

Cohen-Armon, M., Homburg, S., Dantzer, F., Moran, N., Visochek, L., Dekel, N., Priel, E.,
Schwartz, D. \& Rotter, V. (1999) Activation of DNA-bound PARP: A novel target for signal transduction mechanisms. Biochimie 81, S275.

Cookson, M.R., Ince, P.G., Usher, P.A. \& Shaw, P.J. (1999) Poly(ADP-ribose) polymerase is found in both the nucleus and cytoplasm of human CNS neurones. Brain Res. 834, 182-185.

Das, B.R. \& Kanungo, M.S. (1986a) Involvement of ADP-ribosylation in DNA synthesis during development of rat brain. Ind. J. Biochem. Biophys. 23, 87-89.

Das, B.R. \& Kanungo, M.S. (1986b) Developmental changes in the chromatin of the brain of the rat: Analysis by nick translation. Mol. Biol. Rep. 11, 195-197.

Edris, W., Burgett, B., Stine, O.C. \& Filburn, C.R. (1994) Detection and quantitation by competitive PCR of an age-associated increase in a 4.8-kb deletion in rat mitochondrial DNA. Mutat. Res. 316, 69-78.

Grube, K. \& Bürkle, A. (1992) Poly(ADP-ribose) polymerase activity in mononuclear leukocytes of 13 mammalian species correlates with species-specific life span. Proc. Natl. Acad. Sci. U.S.A. 89, 11759-11763.

Lu, C.Y., Lee, H.C., Fahn, H.J. \& Wei, Y.H. (1999) Oxidative damage elicited by imbalance of free radical scavenging enzymes is associated with large-scale mtDNA deletions in aging human skin. Mutat. Res. 423, 11-21.

Masson, M., Niedergang, C., Schreiber, V., Muller S., Menissier-de Murcia, J. \& de Murcia, G. (1998) XRCC1 is specifically associated with 
poly(ADP-ribose) polymerase and negatively regulates its activity following DNA damage. Mol. Cell. Biol. 18, 3563-3571.

Mecocci, P., MacGarvey, U., Kaufman, A.E., Koontz, D., Shoffner, J.M., Wallace, D.C. \& Beal, M.F. (1993) Oxidative damage to mitochondrial DNA shows marked age-dependent increases in human brain. Ann. Neurol. 34, 609-616.

Messripour, M., Weltin, D., Rastegar, A., Ciesielski, L., Kopp, P., Chabert, M. \& Mandel, P. (1994) Age-associated changes of rat brain neuronal and astroglial poly(ADP-ribose) polymerase activity. J. Neurochem. 62, 502-506.

Mishra, S.K. \& Das, B.R. (1992) (ADP-ribosyl)ation pattern of chromosomal proteins during ageing. Cell. Mol. Biol. 38, 457-462.

Mishra, S.K. \& Das, B.R. (1991) Poly(ADP-ribose) synthetase activity in rat testis during ageing; in: Quality Ageing, (Jaiprakash, I., ed.) pp. 47-50, Bangalore.

Muiras, M.L., Muller, M., Schachter, F. \& Burkle, A. (1998) Increased poly(ADP-ribose) polymerase activity in lymphoblastoid cell lines from centenarians. J. Mol. Med. 76, 346-354.

Quesada, P., Faraone-Mennella, M.R., Jones, R., Malanga, M. \& Farina, B. (1990) ADP-ribosylation of nuclear proteins in rat ventral prostate during ageing. Biochem. Biophys. Res. Commun. 170, 900-907.

Realini, C.A. \& Althaus, F.R. (1992) Histone shuttling by poly(ADP-ribosylation) J. Biol. Chem. 267, 18858-18865.

Ruscetti, T., Lehnert, B.E., Halbrook, J., Le Trong, H., Hoekstra, M.F., Chen, D.J. \& Peter- son, S.R. (1998) Stimulation of the DNA-dependent protein kinase by poly(ADP-ribose) polymerase. J. Biol. Chem. 273, 14461-14467.

Salminen, A., Helenius, M., Lahtinen, T., Korhonen, P., Tapiola, T., Soininen, H. \& Solovyan, V. (1997) Down-regulation of $\mathrm{Ku}$ autoantigen, DNA-dependent protein kinase, and poly(ADP-ribose) polymerase during cellular senescence. Biochem. Biophys. Res. Commun. 238, 712-716.

Starke-Reed, P.E. (1997) Oxygen radicals and aging; in Oxygen Radicals and the Disease Process (Craig, T. \& Kalyanaraman, B., ed.) pp. 65-83, Harwood Academic Publishers.

Strosznajder, R.P., Jęśko, H. \& Strosznajder, J. (1999) Aging and amyloid beta related alteration of PARP activity and lipid peroxidation in brain and PC-12 cells in culture. $J$. Neurochem. 73 (Suppl.), S26B.

Tanigawa, Y., Kawamura, M. \& Shimoyama, Y. (1976) Effect of polyamines on (ADP-ribosyl)ation of nuclear proteins from rat liver. Biochem. Biophys. Res. Commun. 76, 406-412.

Ueda, K., Kawaichi, M. \& Hayaishi, O. (1982) Poly(ADP-ribose) synthase; in ADP-Ribosylation reactions: Biology and Medicine (Hayaishi, O \& Ueda, K., eds.) pp. 117-155, Academic Press, New York.

Ueda, K., Inagawa, J., Kido, T., Banasik, M. \& Das, B.R. (1991) Improved assays of poly(ADPribose) metabolizing enzymes (abstract); in: Paul Mandel International Meeting on (ADP-ribosyl)ation Reactions, Quebec, Canada (3 May-2 June) 33c. 